\title{
Occurrence and characterisation of naphthenic acid fraction components in oil residues and sediments stranded on the shoreline of Chedabucto Bay, Nova Scotia, Canada
}

\author{
Zeyu Yang $^{1}{ }^{(0)} \cdot$ Gong Zhang $^{1} \cdot$ Chun Yang $^{1} \cdot$ Keval Shah $^{1} \cdot$ Bruce P. Hollebone $^{1} \cdot$ Sonia Laforest ${ }^{1} \cdot$ Patrick Lambert $^{1}$. \\ Carl E. Brown ${ }^{1} \cdot$ Jane Situ ${ }^{1} \cdot$ Alexandra Verkuyl $^{1}$
}

Received: 16 December 2020 / Accepted: 7 September 2021 / Published online: 26 September 2021

(c) The Author(s) 2021

\begin{abstract}
In June 2016, oil residues and sediment samples were collected from the shoreline of Chedabucto Bay, Nova Scotia, Canada, at sites affected by the 1970 Arrow oil spill. This study aimed to investigate the occurrence, fate, and behaviour of oil components 45 years post-spill by analysing polar naphthenic acid fraction components (NAFCs) through high-performance liquid chromatography-high-resolution mass spectrometry (HPLC-HRMS). In all samples, the most abundant NAFC species were those having only oxygen as the heteroatom $\left(O_{0}\right.$ species, o indicating the number of oxygen atoms, from 1 to 8$)$ and a high degree of saturation. NAFC species only containing two oxygen atoms $\left(\mathrm{O}_{2}\right)$ accounted for $50-70 \%$ of all $O_{\mathrm{o}}$ species. The abundance of all remaining species was negligible compared with $O_{\mathrm{o}}$ species. NAFCs in most Arrow oil residues had higher levels of oxygen species than the oil remaining stored in the sunken tanker. Environmental sediment samples collected from near a marina away from the spill site contained a dominant biological, whereas all Arrow oil residues were mainly composed of NAFCs that are characteristic of petroleum. The abundance of NAFCs in the Arrow oil residues varied between sites, confirming that site-specific environmental conditions play a major role in controlling the fate and behaviour of oil components, including NAFCs.
\end{abstract}

Keywords Naphthenic acid fraction components $\cdot$ Oil residues, Chedabucto Bay $\cdot$ Occurrence $\cdot$ Fate and behaviour

\section{Introduction}

Chedabucto Bay, Nova Scotia, Canada, is an important maritime transportation area with ports that serve as hubs for surrounding industries and regional transportation networks. In 1970 , the tanker Arrow sank on Cerberus Rock $\left(45.47^{\circ} \mathrm{N}\right.$, $\left.61.10^{\circ} \mathrm{W}\right)$. Of the total oil spilled from the wreck, approximately $2000 \mathrm{~m}^{3}$ of Bunker $\mathrm{C}$ fuel was deposited along the southern shores of Chedabucto Bay. Ninety per cent of the spilled oil was not recovered, and much of this fraction reached the beaches and coastlines in Guysborough, Richmond, and Cape Breton counties, including sites as far east as Glace Bay, Lingan, and Dominion (Vandermeulen and

Zeyu Yang

zeyu.yang@ec.gc.ca

1 Emergencies Science and Technology Section (ESTS), Environment and Climate Change Canada, 335 River Road, Ottawa, ON K1A0H3, Canada
Buckley 1985). Oil residues were deposited on the surface or entered into the sediments along the shoreline after the incident (Owens et al. 1994; Vandermeulen and Singh 1994).

In the years following the Arrow sinking, a series of studies have investigated the fate, behaviour, and environmental effects of the spilled oil (Owens et al. 1994, 2008). These studies reported that oil penetrated deep into the sediment to remain as layers or formed asphalt pavement, which eventually became buried under sediment (Owens 1978). The natural attenuation of oil residues varied depending on location(Thomas 1977). At sites where the oil is buried deep within the sediment-a very low energy environmentresidual oil persists in the environment over 20 years from 1970 to 1990 (Vandermeulen and Gordon 1976; Vandermeulen and Singh 1994). Subsurface oil deposits, however, could become re-exposed because of storms or strong wave action (Owens et al. 2006, 2008).

As part of the long-term monitoring of the spilled Arrow oil, samples have been collected 22, 23-30, and 35 years post-spill (Lee et al. 2003; Owens et al. 2006; Wang et al. 
1994). Substantial biodegradation has depleted most resolved components, such as $n$-alkanes and polycyclic aromatic hydrocarbons (PAHs), particularly within the near-surface deposits. Some triterpenes, hopanes, and steranes persist as relatively conservative biomarkers (Lee et al. 2003; Wang et al. 1994). Subsurface residues remain sequestered and unaltered; the degradation of these oil residues requires substantial changes to the environmental conditions along the local shoreline (Owens et al. 2006). Significant sediment toxicity was observed for amphipod survival tests for sediments collected 23-30 years post-spill (Lee et al. 2003). Unfortunately, it is not clear what petroleum components have contributed to the sediment toxicity.

In the summer and fall 2015, oil leaked from the sunken vessel. This released oil re-covered some sections of local shoreline. In June 2016, Environment and Climate Change Canada (ECCC) launched a shoreline survey of the shoreline of Chedabucto. The status of oil contamination and the degree of weathering (46 years post-spill) of oil residues from the 1970 Arrow spill would be investigated (Yang et al. 2018). These investigation relied on the analysis of total petroleum hydrocarbons (TPH), $n$-alkanes, petroleumrelated biomarkers, polycyclic aromatic hydrocarbons (PAHs), and their alkylated congeners (APAHs). It was found that the sources of petroleum hydrocarbons for the environmental sediment samples varied from sampling sites, which were released recently through human activities, or were Arrow oil residues. The depletive loss of $n$-alkanes and APAHs in most of the Arrow oil residues suggested that various weathering processes had contributed to their aging with microbial degradation being the dominant process; however, the extent of weathering and alteration of oil residues varied depending on environmental conditions.

All the earlier studies of oil residues from the Arrow (Lee et al. 2003; Owens et al. 2006, 2008; Vandermeulen and Singh 1994; Wang et al. 1994; Yang et al. 2018) investigated only components detectable by gas chromatography (GC). Except for these GC-detected targets, there exist many oxygenated intermediates, produced through the biodegradation and (or) photo-oxidation of oil. These intermediates are usually characterised by low volatility, high polarity, and high bioavailability due to the addition of oxygen. They act as the important role to enhance the toxicity to aquatic organisms (Clemente and Fedorak 2005; Frank et al. 2009, 2008; Vanderveen et al. 2017), and make up the major components of severely weathered oils (Aeppli et al. 2012). Naphthenic acid fraction compounds (NAFCs), a class of these oxygenated intermediates, contain a diverse family of carboxylic acids and other acid-extractable organic compounds that vary in structure (e.g., aromatic, adamantane, or diamondoid structures) and species (e.g., sulphur- and nitrogen-containing compounds and multiple oxygenated acids) (Rowland et al. 2011). Different oils contain different chemical characteristics of NAFCs and naphthenic acids (NAs) depending on the origin and weathering status of oil in the natural environment (Yang et al. 2019). Here NAs are a family of cycloaliphatic carboxylic acids with an empirical formula of $\mathrm{C}_{n} \mathrm{H}_{2 n+z} \mathrm{O}_{2}$, where $n$ is the number of carbon, $z$ is zero or negative even integer presenting the hydrogen deficiency of a NA molecule. In addition, the bio- or photodegradation of oil components increases the abundance and alters the characteristics of NAFCs or NAs within oil-water mixtures due to the preference bio- or photo-oxidation of aliphatic, cyclic and aromatic hydrocarbons (Ray et al. 2014; Yang et al. 2017b). Some researchers found that the concentration of NAs are much higher than those of PAHs in sediment samples collected from the Hebei Spirit oil spill (Wan et al. 2014). NAFCs were found to be recalcitrant to biodegradation (Wan et al. 2014), therefore, analysing these oxygenated intermediates is an alternative fingerprinting technique to evaluate oil contamination, reveal the fate and behaviour of oil components in the environment, and aid us to identify the weathering mechanisms of oil after a spill.

In this study, samples collected from Chedabucto Bay, Nova Scotia, are analysed by high-performance liquid chromatography-ultra-high-resolution Orbitrap mass spectrometry combined with electrospray ionisation in the negative mode (HPLC-HRMS) to identify NAFCs. We investigate the variability of the chemical composition of NAFCs among sample sites and provide the compositional characteristics of polar NAFCs. These analyses provide a better understanding of the fate of spilled oil in relation to natural attenuation, and serve as a tool for identifying petroleum sources. No certified reference materials exist, as of yet, for identifying and quantifying NAFCs because of the complex chemical composition of these compounds. We, therefore, generate average mass spectra to identify NAFCs according to their elemental composition within each sample. All values reported in this study must, therefore, be regarded as semi-quantitative because the reported results are the relative abundance normalised to the response of internal standard and the weight of oil/total solvent extractable materials (TSEM) in each sample.

\section{Experimental section}

\section{Sampling}

The sampling strategies and sample information are described in Yang et al. (2018). In this study, we analysed nine environmental samples (collected from sites located between $45.268^{\circ} \mathrm{N}, 61.022^{\circ} \mathrm{W}$, and $45.615^{\circ} \mathrm{N}, 61.365^{\circ} \mathrm{W}$ ), as well as two additional oil samples. Most of the nine environmental samples were oil mixed with sediment or were oil residues recovered from the surface of rocks or 
from under or between rocks. They are two oil residues from Cape Auguet, four oil residues from Black Duck Cove, one oil residue from Indian Cove, and two sediments from within and around the marina at Hawkesbury (see Table 1 for more details of the samples). An initial investigation demonstrated that recently released petroleum had contaminated both samples from around Port Hawkesbury, because the petroleum hydrocarbons in these two sediments did not show weathered characteristic like the Arrow oil residues. Specifically, the mixed biogenic and petrogenic $n$-alkanes were present in them. Light APAH families $\left(C_{\mathrm{i}}-\mathrm{N}\right.$ and $\left.C_{\mathrm{i}} \mathrm{-P}\right)$ were usually higher in abundance than the other heavier groups in the two sediment samples. Most APAH groups $\left(C_{\mathrm{i}}-\mathrm{N}, C_{\mathrm{i}}-\mathrm{P}, C_{\mathrm{i}}-\mathrm{D}, C_{\mathrm{i}}-\mathrm{Fl}\right.$, and $C_{\mathrm{i}^{-}}$ B) showed a typical bell shape pattern as the degree of alkylation increased $\left(C_{0}<C_{1}<C_{2}<C_{3}>C_{4}\right)$. On the other hand, Arrow oil residues usually had the most abundant $C_{\mathrm{i}}$-B group, followed by $C_{\mathrm{i}}-\mathrm{P}, C_{\mathrm{i}}-\mathrm{D}$, and $C_{\mathrm{i}}-\mathrm{C}$, and then the other groups for APAH families. In each APAH group, their concentration increased with the increased degree of alkylation (Yang et al. 2018). The seven remaining samples represented the historical contamination from the sunken Arrow. For this study, two additional oil samples were collected and analysed for comparative purposes: (i) an Arrow oil sample recovered directly from the sunken tanker, and (ii) a naturally weathered oil residue sample collected from a site that was re-oiled by the release of Arrow oil in 2015. The Canadian Coast Guard collected and provided both of these samples. Not all the collected samples were analysed in this study although all of them were analysed for conventional petroleum hydrocarbons, and all the samples were classified into three groups in terms of the chemical characteristics in our previous study (Yang et al. 2018). Herein, only representative environmental samples were analyzed to represent oil residues from the Arrow oil spill and sediments with recently released oil. These representative samples are enough to reflect the variation of NAFCs for samples with different oil source contribution, and to help us understand the natural attenuation processes of spilled oil in the environment.

\section{Chemicals and materials}

Most chemicals and standards were supplied by Sigma-Aldrich (Bellefonte, PA, USA) and Sigma-Aldrich (Oakville, ON, Canada), including LC/MS-purity acetic acid, formic acid, and ammonium acetate, toluene, HPLC grade methanol, isopropanol, and acetonitrile, and deuterated fatty acids (such as $\left[{ }^{2} H_{15}\right]$ caprylic acid (C8:0- $\left.d_{15}\right)$, $\left[{ }^{2} \mathrm{H}_{2}\right]$ palmitic acid $\left(\mathrm{C} 16: 0-d_{2}\right)$, and $\left[{ }^{2} \mathrm{H}_{39}\right]$ eicosanoic acid $\left.\left(\mathrm{C} 20: 0-d_{39}\right)\right)$. All other solvents used are of the highest purity (Caledon, Georgetown, ON, Canada). Ultra-pure water was prepared from a Milli-Q water purification system (Millipore, Billerica, MA, USA). Silica gel (100-200 mesh) was supplied by Spectrum Chemicals (Gardena, CA, USA).

\section{Sample extraction, clean-up, and analysis}

Sample extraction procedures followed the methods presented in a previous study (Yang et al. 2017a). In brief, an aliquot of sediment (approximately $10 \mathrm{~g}$ wet weight) thoroughly mixed with sodium sulphate was spiked with appropriate amount of deuterated fatty acids as surrogates, including octanoic acid (C8:0- $\left.d_{15}\right)$, and eicosanoic acid $\left(\mathrm{C} 20: 0-d_{39}\right)$. The mixture was then Soxhlet-extracted with dichloromethane (DCM) for $16 \mathrm{~h}$. Oil samples were diluted directly with DCM. Appropriate amounts of diluents, spiked with same surrogates as sediment, were then transferred for fractionation. Oil residue samples spiked with same surrogates as sediment were ultrasonicated consecutively three times with DCM. Appropriate extracts or diluents were loaded into a column ( $5 \mathrm{~mm}$ i.d.) with $1 \mathrm{~g}$ of silica gel topped with $1 \mathrm{~cm}$ of anhydrous $\mathrm{Na}_{2} \mathrm{SO}_{4} .10 \mathrm{~mL}$ of DCM was used to remove interference from the target components.
Table 1 Sample information including sampling date, site characteristics, and location

\begin{tabular}{lll}
\hline ESTS code & Sample information & Longitude (N), latitude (W) \\
\hline $2016 / 06 / 08-3163$ & Cape Auguet segment 2 oil under rocks & 45.46867 N, 61.02216 W \\
$2016 / 06 / 08-3165$ & Cape Auguet segment 2 oil under rocks & $45.4686 \mathrm{~N}, 61.02224 \mathrm{~W}$ \\
$2016 / 06 / 08-3179$ & Black Duck Cove segment 1 (rocks), UIZ & 45.27284 N, 61.03024 W \\
$2016 / 06 / 08-3184$ & Black Duck Cove, segment 1 (rocks), UIZ & 45.27266 N, 61.03056 W \\
$2016 / 06 / 08-3186$ & Black Duck Cove segment 1 (oil under rocks), UIZ & 45.27257 N, 61.03076 W \\
$2016 / 06 / 08-3193$ & Black Duck Cove segment 3 (oil on rocks), UIZ & 45.26755 N, 61.03476 W \\
$2016 / 06 / 08-3247$ & Port Hawkesbury near marina, LIZ & 45.61484 N, 61.36554 W \\
$2016 / 06 / 08-3251$ & Port Hawkesbury at marina, MIZ & 45.61487 N, 61.36548 W \\
$2016 / 06 / 22-3281$ & Source oil samples from the sunken tanker in 2015 & / \\
$2016 / 06 / 22-3282$ & Naturally weathered source oil spilled in 2015 & / \\
\hline
\end{tabular}

LIZ represents lower intertidal zone; UIZ represents upper intertidal zone; and MIZ represents middle intertidal zone. " " indicates data are not available 
Another $7 \mathrm{~mL}$ of methanol containing $0.1 \%$ formic acid was used to elute the polar targets. The eluted material was then dried by gentle $N_{2}$ and reconstituted in $1 \mathrm{~mL}$ of HPLC grade isopropanol, using $1.0 \mu \mathrm{g} / \mathrm{mL}$ of deuterated palmitic acid $\left(\mathrm{C} 16: 0-d_{2}\right)$ as an internal standard (IS). All samples were centrifuged at $3000 \mathrm{rpm}$ for $10 \mathrm{~min}$ prior to HPLC-HRMS analysis.

\section{HPLC-HRMS analysis of NAFCs}

The analytical methods were adapted from Zhang et al. (2014). Briefly, sample analysis was performed using an Accela HPLC system paired with an Exactive Orbitrap Mass System (Thermo Fisher Scientific, San Jose, CA, USA) with the electrospray ionisation (ESI) source in a negative ion mode. A 20 min LC gradient method was used for separation with a Poroshell 120 EC- $C_{8}$ column $(100 \times 2.1 \mathrm{~mm}$ i.d., $2.7 \mu \mathrm{m}$, Agilent) at a flow rate of $0.25 \mathrm{~mL} \cdot \mathrm{min}^{-1}$. The gradient method was programmed among three mobile phases: mobile phase $\mathrm{A}$, water with $0.0025 \%$ of formic acid; mobile phase $\mathrm{B}, 95 \% / 5 \%$ acetonitrile/water with $3 \mathrm{mmol} / \mathrm{L}$ ammonium acetate; and mobile phase $\mathrm{C}, 85 \% / 10 \% / 5 \%$ isopropanol/toluene/water with $3 \mathrm{mmol} / \mathrm{L}$ ammonium acetate. Initially, the $95 \%$ mobile phase $\mathrm{A}$ and $5 \%$ mobile phase $\mathrm{B}$ were held isocratically for $2 \mathrm{~min}$, followed by a linear increase from 5 to $100 \%$ of the mobile phase B over $8 \mathrm{~min}$. Over the following $5 \mathrm{~min}$, the mobile phase B decreased to $10 \%$; the mobile phase $\mathrm{C}$ increased linearly to $90 \%$. And then both mobile phases were held at these percentages for $10 \mathrm{~min}$. Mobile phase B increased to $100 \%$ over $30 \mathrm{~s}$ and was then held at this percentage for $90 \mathrm{~s}$. After this, the mobile phase B decreased to 5\%. Mobile phase A increased to $95 \%$ over $30 \mathrm{~s}$ and was held at this level for $5 \mathrm{~min}$ prior to the next injection. The Orbitrap mass spectrometer was operated in ESI negative mode (ESI-). Data were acquired in full scan with a mass to charge $(\mathrm{m} / \mathrm{z})$ ratio ranging from 80 to 1600 . The negative ion of the acetic acid dimer (2M-1, $m / z=119.03498)$ was used as a lock mass for scan-to-scan calibration correction to ensure $<2 \mathrm{ppm}$ mass accuracy. The mass parameters were set at a spray voltage of $4.0 \mathrm{kV}$ and a capillary temperature of $320{ }^{\circ} \mathrm{C}$; the settings for the tube lens, sheath gas and auxiliary gas were set at $-90 \mathrm{~V}$, $45 \mathrm{~mL} \mathrm{~min}^{-1}$, and $15 \mathrm{~mL} \mathrm{~min}^{-1}$, respectively.

Heteroatom-containing species, including those having a formula of $C_{\mathrm{c}} H_{\mathrm{h}} N_{\mathrm{n}} O_{\mathrm{o}} S_{\mathrm{s}}$, where c, h, n, o, and s are the elemental numbers of carbon, hydrogen, nitrogen, oxygen, and sulphur in the formula $(6 \leq \mathrm{c} \leq 160,6 \leq \mathrm{h} \leq 122$, $0 \leq \mathrm{o} \leq 8,0 \leq \mathrm{n}$, and $\mathrm{s} \leq 2$ ), were detected as deprotonated molecules, which are $[\mathrm{M}-\mathrm{H}]^{-}$ions, by the Orbitrap MS ESIscan. Spectral interpretation of the NAFC was obtained to retrieve the average mass spectra over a retention time of 5-40 min. Elemental formulae were generated at a mass accuracy of $2 \mathrm{ppm}$ and assigned based on $\mathrm{m} / \mathrm{z}$ values by the
Xcalibur software package (Thermo Fisher Scientific, San Jose, CA, USA). The MS data were processed; the elemental composition of the compounds was determined by measuring the accurate $\mathrm{m} / \mathrm{z}$ values. A resolving power $\left(\mathrm{m} / \Delta \mathrm{m}_{50 \%}\right)$ of approximately 100,000 and a mass accuracy of $<2 \mathrm{ppm}$ provided unambiguous molecular formula assignments for the single-charged molecular ions. Double-bond equivalent (DBE) values represent the number of rings and the number of carbon double bonds in a given molecular formula, which is calculated using equation (Eq. 1) for the elemental formula of $C_{\mathrm{c}} H_{\mathrm{h}} N_{\mathrm{n}} O_{\mathrm{o}} S_{\mathrm{s}}$ (McLafferty and Turecek 1993):

$D B E=c-\frac{h}{2}+\frac{n}{2}+1$.

Isotopes, adducts, and minors were excluded from NAFC analysis. Because there are no weathering-resistant biomarkers for the Orbitrap MS available for normalising the data set, the responses for $\mathrm{m} / \mathrm{z}$ peaks, relying on the assigned molecular formulae, were normalised to the abundance of the internal standard and oil/TSEM weight of each mass spectrum. This normalisation can partially eliminate detection bias in the ESI response caused by sample matrix effects and/or ionisation suppression effects because ionisation suppression will cause an apparent reduction in analyte recovery from different matrices when the ESI is used in a negative ion mode(Page et al. 2007).

\section{Quality control and quality assurance}

Sodium sulphate spiked with an equal amount of surrogates was prepared for the blank control test. The same analytical procedures were run through the blank controls to evaluate the background contribution to NAFC analysis. All reported NAFC data were background corrected. The surrogate recoveries were determined as $83 \pm 18 \%$ for $\mathrm{C} 8: 0-d_{15}$ and $87 \pm 20 \%$ for $\mathrm{C} 20: 0-d_{39}$ when compared to the response of the authentic standards.

\section{Results and discussion}

\section{Chemical characteristics of acidic extractable components}

All total ion chromatograms (TICs) in negative-ion ESI mode for the representative samples are presented in Fig. S1. The TICs represent the total acidic components present in the samples, which may contain sulphur, oxygen, and/or nitrogen heteroatoms. Visualisation analysis indicated that the abundance of acidic extracts varied between samples; for example, the NAFC composition in the two source oils differed somewhat. A greater abundance of resolved and unresolved peaks was eluted prior to 23 min for Sample 3281, 
which was collected directly from the sunken tanker in 2015 , relative to Sample 3282, the weathered oil residue from the 2015 spill. Sample 3281 also produced more unresolved peaks between 23 and 29 min than Sample 3282.

The $C_{8}$ column was used for liquid chromatographic separation in this study, so hydrophobic molecules in the polar mobile phase tend to adsorb to the hydrophobic $C_{8}$ stationary phase, whereas hydrophilic molecules in this phase passing through the column faster than the hydrophobic molecules. The relatively higher abundance of the earlier eluted peaks attests to acidic components, which have a higher polarity, being more abundant in Sample 3281 than in Sample 3282. This pattern is expected as Sample 3282 was weathered after spilled into the environment, and Sample 3281 remained stored in the sunken vessel.

The pair of Arrow oil residues collected from Cape Auguet (Fig. S1b) and the four Black Duck Cove samples (Fig. S1c) presented similar patterns at the various retention times. Specifically, a hump having observed resolved peaks in the TIC was present prior to $23 \mathrm{~min}$, and another hump, but lacking obvious resolved peaks, occurred between 23 and $31 \mathrm{~min}$. The abundance varied between the samples in some cases. Two oil residues from Black Duck Cove (Samples 3184 and 3186), for example, differed from each other despite both being sampled from the upper tidal zone; however, Sample 3184 was collected from rock surfaces, whereas Sample 3186 was obtained from under rocks. As shown by Yang et al. (2017b), certain high molecular weight $n$-alkanes were present in Sample 3184, but they were not observed in Sample 3186. Sample 3186 had more abundant NAFCs than Sample 3184 (see below).

Both samples from Cape Auguet were collected from under rocks, and the TIC spectra of both illustrated a very similar abundance upon visual inspection. The two samples from the Port Hawkesbury marina area also presented similar NAFC patterns for the various retention times. The spectra of both Port Hawkesbury samples had more resolved peaks and higher abundances than the above-mentioned oil and oil residues. This was especially true for Sample 3247. For the Port Hawkesbury samples, lighter molecular weight NAFCs were dominant. Nonetheless, abundances differed between the two samples, a dissimilarity that could be ascribed to discrepancy in either sample weight and/or the specific sampling site (Fig. 1).

Figure 2 presents the average spectra for several representative samples. NAFC abundance and peak numbers in all Arrow oil residues (except Sample 3282) were higher than those of Sample 3281, the stored source oil. Sample 3282 presented a limited number of peaks, in particular when the $m / z$ was $<400$. Most $m / z>400$ had a lower abundance than that of the Arrow source oil. Visual inspection of the average spectra revealed that the most abundant peaks did not shift to a lower/higher mass for the heavily weathered or even partially weathered Arrow oil. This lack of change prevents the identification of the source Arrow oil from the oil residues. Natural weathering processes, such as photo-oxidation or microbial degradation, can form abundant NAFCs having a short carbon chain length through the oxidation of non- to medium-polar petroleum hydrocarbons or the intermediates of aldehydes or ketones (Aeppli et al. 2012; Yang et al. 2017b). In the natural environment, NAFCs are usually resistant to biodegradation due to the presence of double bond equivalents and high carbon numbers (Zhang et al. 2016); however, NAFC species with more carbons and increasing number of rings or double bond equivalents are preferentially photo-oxidized to low molecular intermediates (Leshuk et al. 2016). The low molecular weight NAFCs have been found to have relatively higher water solubility, be more susceptible to microbial activity and bioavailability (Frank et al. 2009, 2008). Therefore, the formed short carbon chain length NAFCs may have dissolved in water phase, and washed away from the oil residues by waves; NAFCs having more carbons may have been photo-oxidized as all these oil residues were collected from the surface exposed to air.

Similarly, the two samples from around the marina at Port Hawkesbury (Fig. 2d) had fewer peaks compared with most Arrow oil residues and the source oil. This was particularly true toward the light end, which showed marked differences for most Arrow oil residues. This discrepancy occurred as the sources of these identified acidic components were not identical. As concluded by Yang et al. (2018), the identified $n$-alkanes and petroleum biomarkers of terpanes and steranes of the pair of samples from Port Hawkesbury reflected terrestrial input as the major source with a minor contribution from petroleum hydrocarbons. Specifically, the significant amounts of $n-C_{25}, n-C_{27}, n-C_{29}$, and $n-C_{31}$ congeners suggested the major terrestrial input, while the low amount of light molecular weight $n$-alkanes and petroleum biomarkers indicated the minor petroleum input. APAH analysis also showed naphthalenes and phenanthrenes to be the most abundant families; therefore, oil contamination in these two samples was lighter and fresher than all oil residues from the Arrow. The Port Hawkesbury samples, therefore, have a lower abundance of resins and asphaltenes, and NAFCs in these samples containing more recently released petroleum (Yang et al. 2017b). Similar to the weathered tars, oxygenated intermediates, like acidic components and in particular heavy molecular weight components, are supposed to increase with weathering (Katarina Huba and Gardinali 2016). However, NAFCs are oxygenated intermediates; further degradation can markedly decrease their abundance in strongly weathered oil. Identified NAFCs in some samples can also reflect biogenic sources due to the presence of NAFCs having the sign of even-to-odd preference (Cheung et al. 2010; Dunn et al. 2008) (see the following sections for details). This is particularly true for Samples 3282, 3247, 


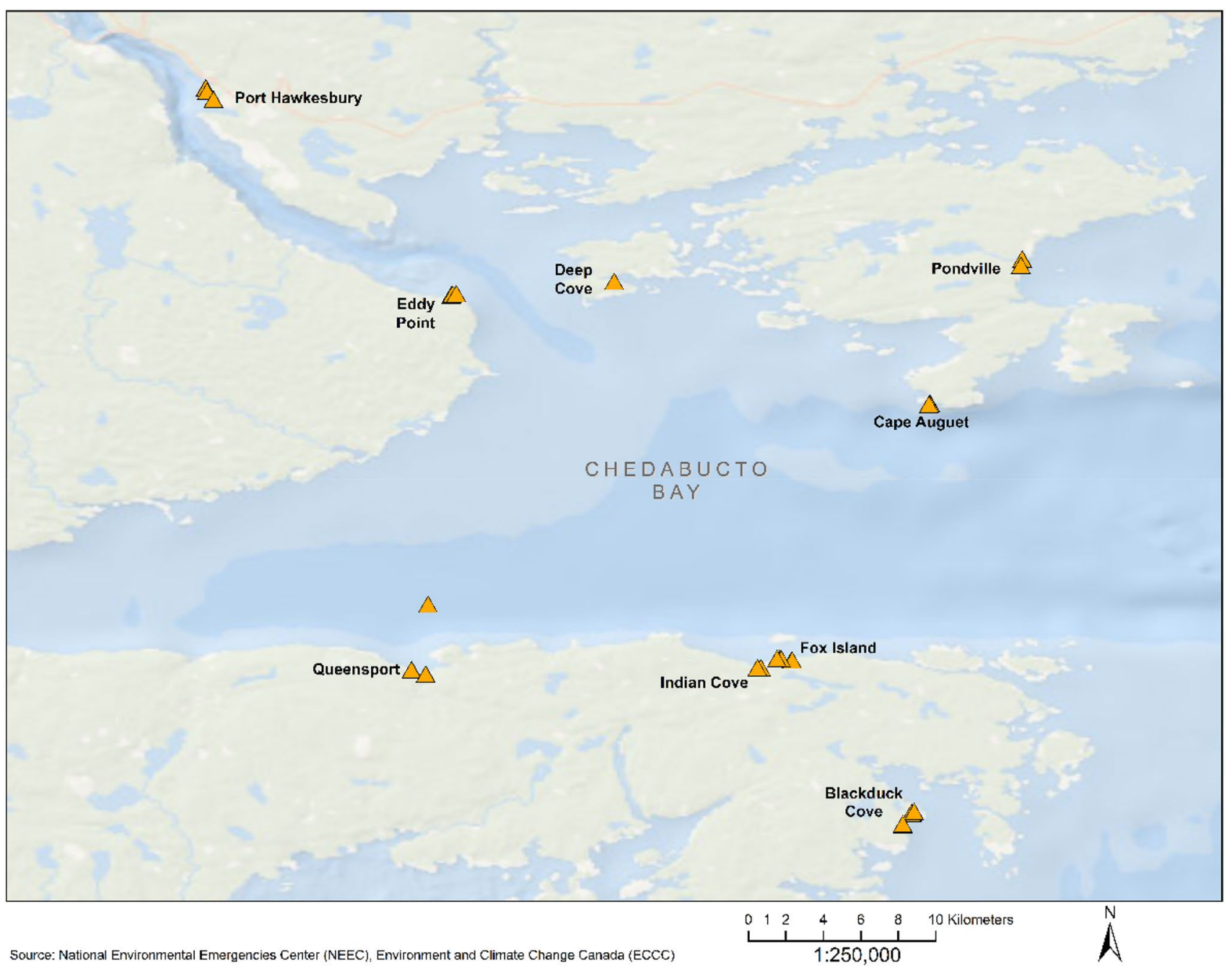

Fig. 1 Sampling locations around Chedabucto Bay, Nova Scotia, Canada

and 3251, each presenting several peaks in abundance when $m / z<300$.

Because of the possible background interference, as well as variable sample weights and/or ionisation efficiencies of ESI between samples, in the following section, we discuss the specific acidic classes that contain various heteroatoms after normalising them by the abundance of internal standard and the oil or TSEM weight.

\section{Distribution of total heteroatom class identified in different samples}

HRMS can identify various petroleum components based on exact masses, and generate the corresponding molecular formula. Thus, the identification of NAFCs in our study relies mainly on the elemental composition derived from the HRMS characterization. This situation arises because of the poor separation efficiency of NAFC congeners/isomers by LC and the limited commercial availability of authentic NAFC standards. We grouped compounds into classes within a sample based on their heteroatom class using the assigned elemental composition for each $\mathrm{m} / \mathrm{z}$ peak. For example, those contain only oxygen heteroatoms were grouped as $O_{\mathrm{o}}$ species with the formula of $\mathrm{C}_{\mathrm{c}} \mathrm{H}_{\mathrm{h}} O_{\mathrm{o}}$; those contain N, S, and oxygen heteroatoms were grouped as $N_{\mathrm{n}} S$ ${ }_{\mathrm{s}} \mathrm{O}_{\mathrm{o}}$ species; those contain $\mathrm{N}$ and oxygen heteroatoms were grouped as $N_{\mathrm{n}} O_{\mathrm{o}}$ species; and those contain $\mathrm{S}$ and oxygen heteroatoms were $S_{\mathrm{s}} O_{\mathrm{o}}$ species (Yang et al. 2017b). The most abundant acidic heteroatom class for all samples were $O_{\mathrm{o}}$ species. They accounted for 57-76\% of total acidic components among all samples, followed by $N_{\mathrm{n}} S_{\mathrm{s}} O_{\mathrm{o}}$ species, which accounted for $18-33 \%$ of the total acidic components. Other species provided a minor contribution to total NAFCs (Fig. S2).

The abundance and distribution of heteroatom classes varied between samples. In terms of heteroatom abundance 
(a)
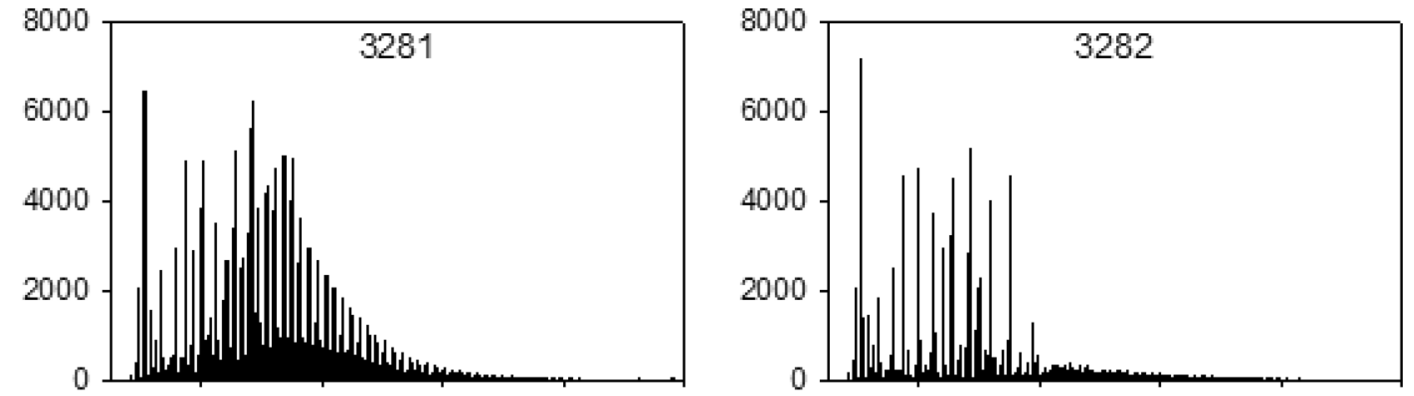

(b)
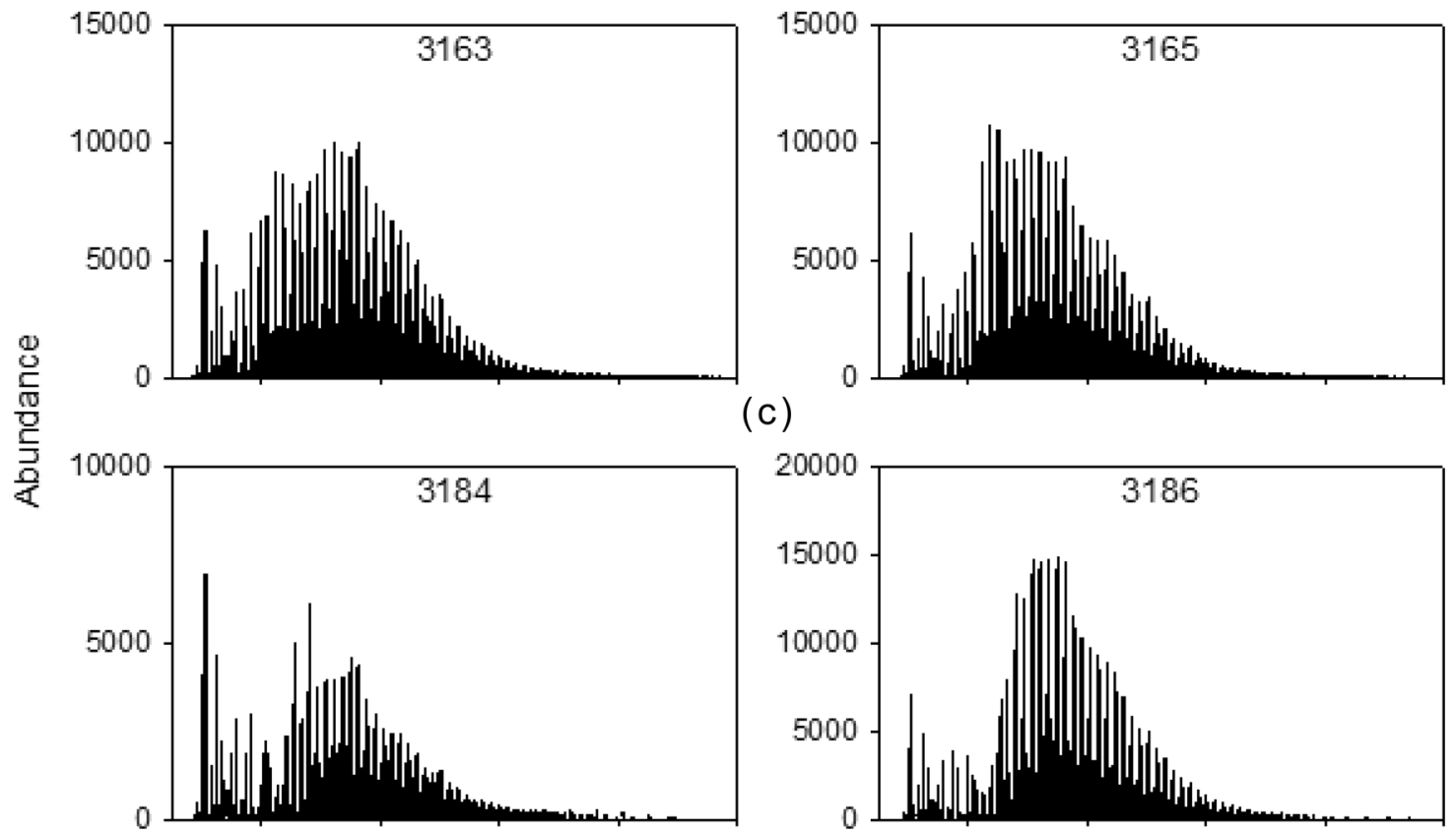

(c)

(d)
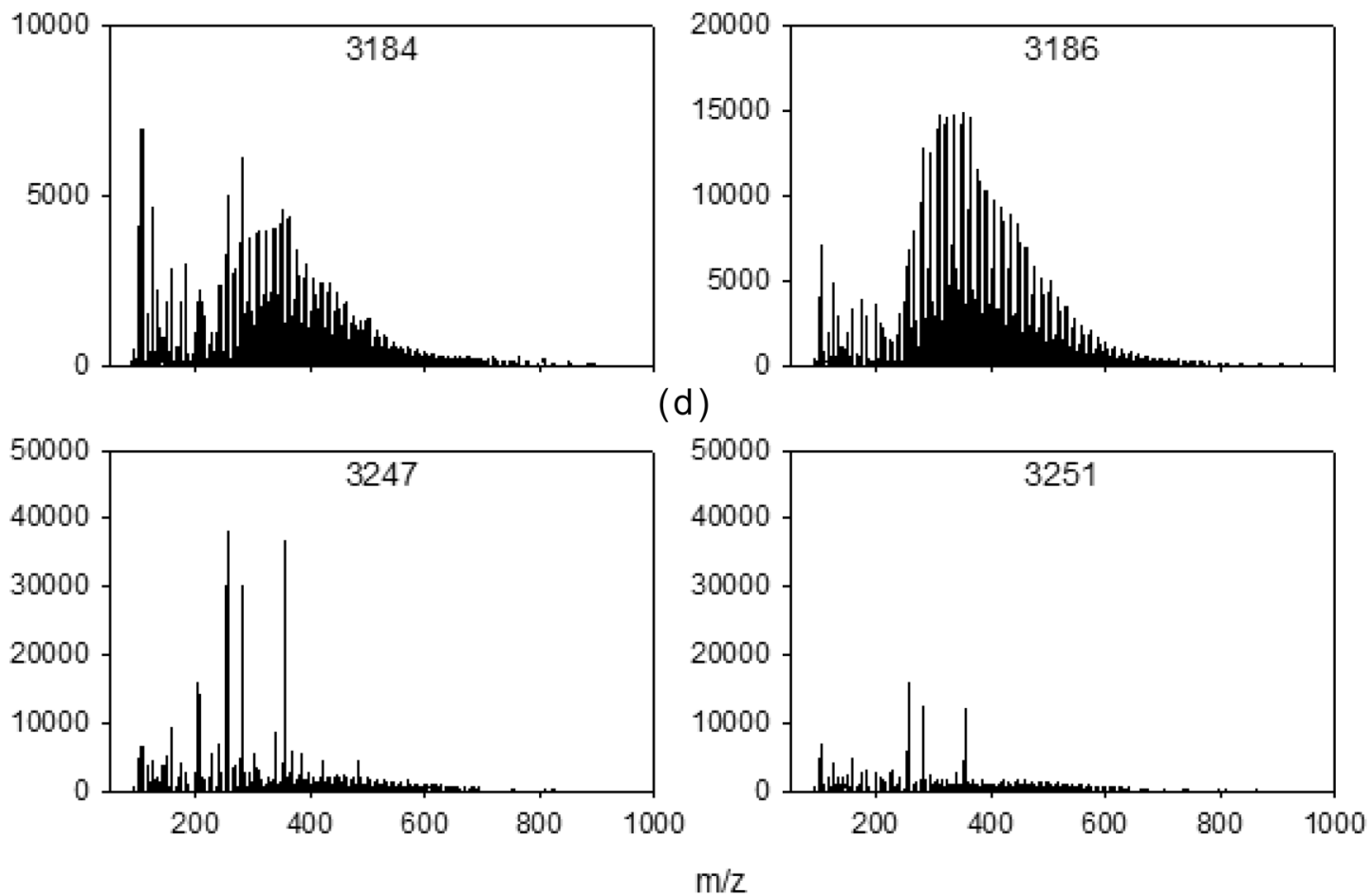

Fig. 2 Average negative-ion ESI orbitrap mass spectra of the acidic extractable fractions for representative samples. a Source oil from the Arrow spill; b Arrow oil residues collected from Cape Auguet;

c Arrow oil residues collected from Black Duck Cove; d sediments from the Port Hawkesbury marina area

of the various samples-Fig. 3 presents major species having a $>0.1 \%$ abundance of the internal standard in each injection in the ESI (-)-Orbitrap MS-the two source oils had a lower abundance than other samples; this is particularly true for the weathered oil sample spilled in 2015 (Sample 3282, Fig. 3a). Sample 3247, collected from near the marina in Port Hawkesbury, had the highest abundance of $O_{\mathrm{o}}$ species (Fig. 3d). The abundance of 

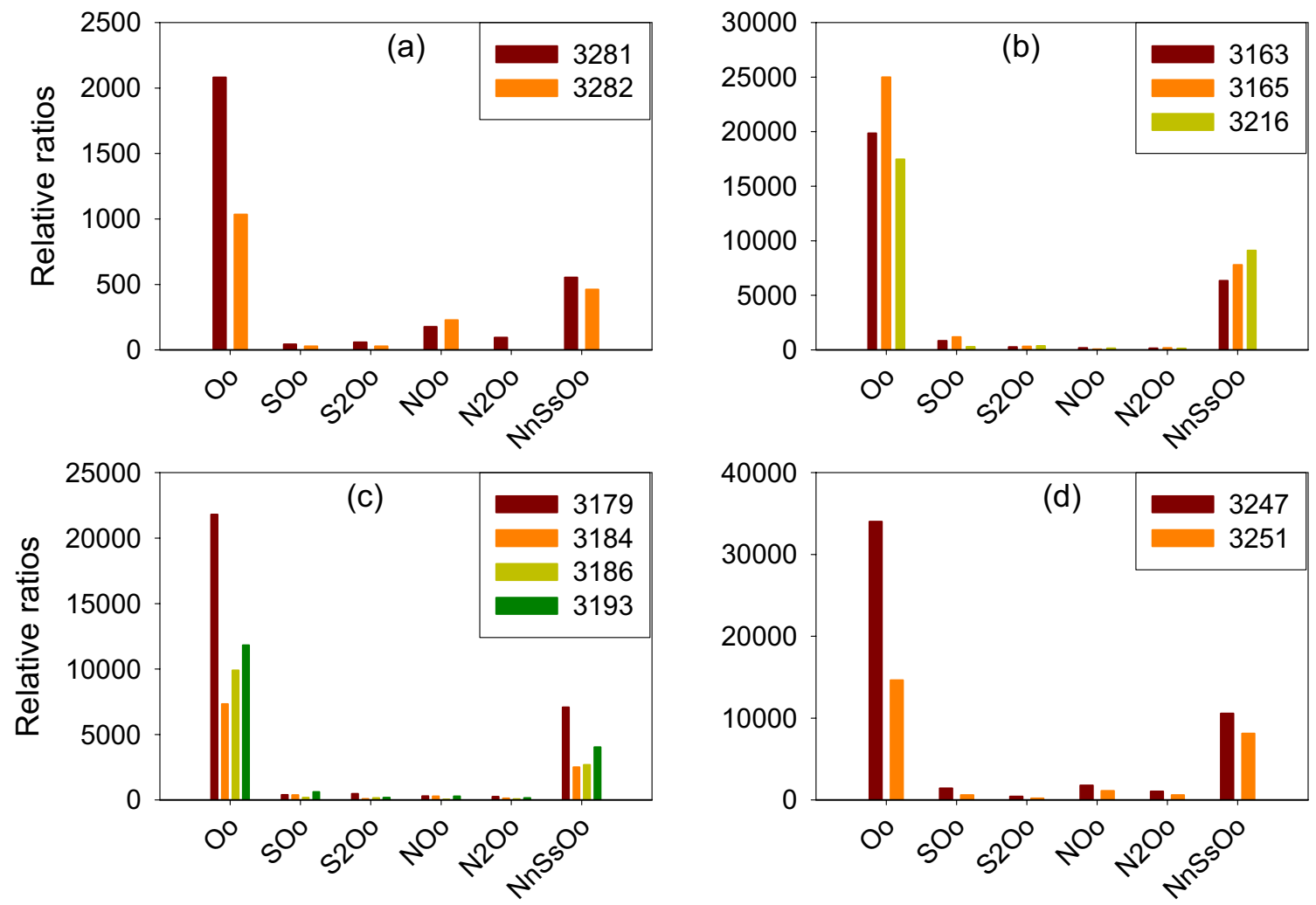

Fig. 3 Relative ratios of the different species subtotals. a Source oil from the Arrow spill; b Arrow oil residues collected from Cape Auguet; c Arrow oil residues collected from Black Duck Cove; $\mathbf{d}$ sediments from the Port Hawkesbury marina area

$O_{\text {o }}$ species then decreased in the order of the two samples from Cape Auguet (Fig. 3b), a sample from Indian Cove (Fig. 3b), and a sample from Black Duck Cove (Fig. 3c). The samples from Port Hawkesbury (Fig. 3d) and Indian Cove (Sample 3216 in Fig. 3b) contained the highest abundance of $N_{\mathrm{n}} S_{\mathrm{s}} O_{\mathrm{o}}$ species, followed by Sample 3179 from Black Duck Cove (Fig. 3c), and then the remaining oil residues. Given that the abundance of these semi-quantitative species varied between sampling sites within the same area, we can infer that sampling site plays an important role in controlling the fate of these identified NAFCs, a finding similar to that from the analysis of conventional petroleum hydrocarbons (Yang et al. 2018).

The elemental composition of these acidic species varies in terms of carbon, sulphur, oxygen, and nitrogen numbers, as well as the number of double bonds/naphthenic rings. Each ring or double bond in a molecule reduces the number of hydrogen atoms by two (Lemkau et al. 2014). DBE, representing the number of rings plus double bonds, is a useful parameter for examining the compositional differences between samples. As $O_{\mathrm{o}}$ species formed the most abundant group in all major classes, in the following section, we address the distribution profiles of total $O_{\mathrm{o}}$ species versus carbon number, DBE values, and oxygen numbers between samples.

\section{Characteristics of $O_{0}$ species}

\section{$O_{0}$ species versus carbon number}

In plots of the relative abundance of subtotal $O_{\mathrm{o}}$ species versus carbon number $\left(C_{6}\right.$ to $\left.C_{60}\right)$, the Arrow source oil and most Arrow oil residues presented a typical single bell shape, having a maximum of species at carbon numbers 21 to 24 (Fig. 4). Several samples (Samples 3282, 3179, 3247, and 3251), however, presented double peaks. More specifically, the most abundant peak occurred at carbon numbers 16-22 with a strong predominance of even-over-odd carbon numbers. The second abundant peak, occurring around carbon number 30, did not show an obvious predominance of evenover-odd carbon numbers. The importance of short-chain compounds and the strong predominance of even-over-odd carbon numbers at carbon numbers 16-22 indicate that biological inputs represent a major source in these samples (Cheung et al. 2010; Dunn et al. 2008). At the same time, the presence of abundant long-chain compounds lacking a clear 
(a)

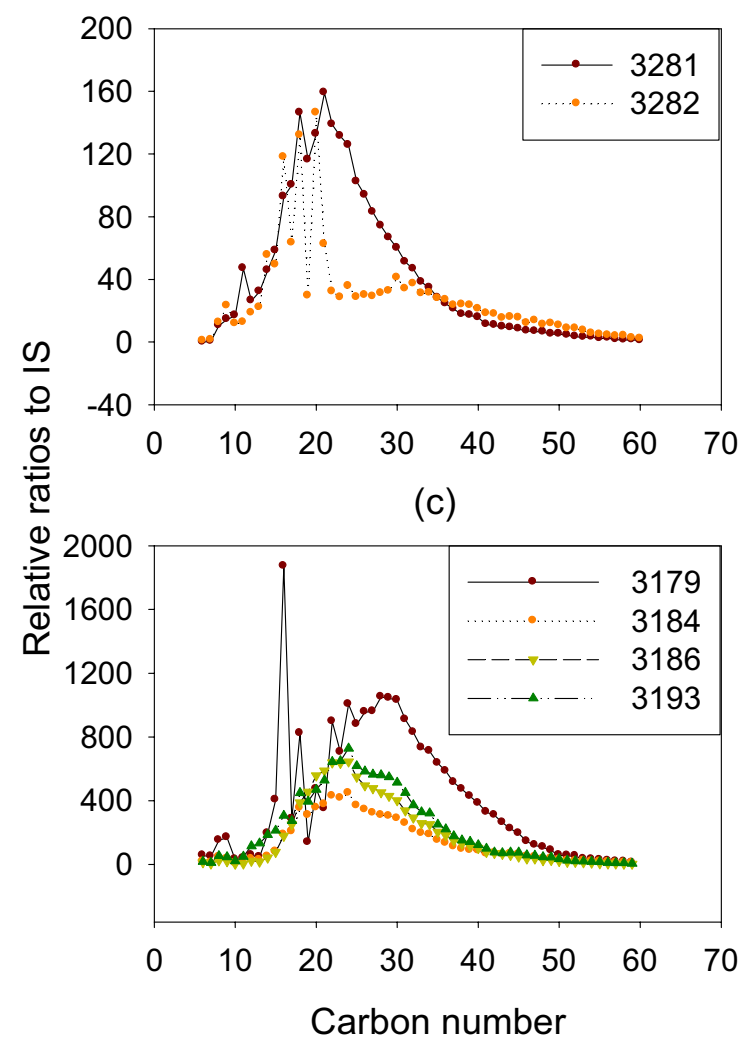

(b)

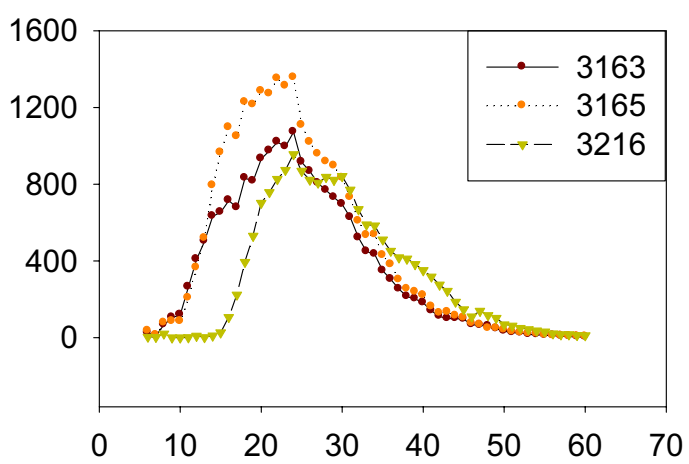

(d)

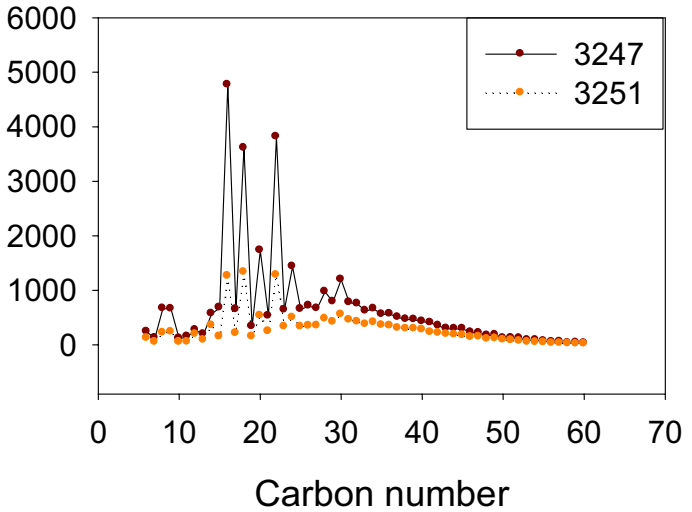

Fig. 4 Distribution profiles of total $O_{\mathrm{o}}$ species versus carbon number. a Source oil from the Arrow spill; b Arrow oil residues collected from Cape Auguet; c Arrow oil residues collected from Black Duck Cove; d sediments from the Port Hawkesbury marina area

predominance of even-over-odd carbon numbers indicates that another source is responsible for the petroleum input (Headley et al. 2016).

As discussed above, the abundance of $O_{0}$ species with different carbon numbers varied between samples, regardless of the existing patterns. For single bell-shaped samples, the carbon numbers of the most abundant $O_{\mathrm{o}}$ species differed between the source oil and the weathered Arrow oil residues. For example, Sample 3281, the source oil, had a maximum abundance at carbon number 21 , whereas all other oil residues produced a maximum abundance peak at carbon number 24.

Lower molecular weight NAFCs are considered to be more biodegradable and more water soluble than higher molecular weight NAFCs (King et al. 2014; Ray et al. 2014). The weathering recalcitrant NAFCs will accumulate in oil residues through a long-term natural weathering; therefore, oil residues that experience depletive weathering processes should have heavier molecular weight $O_{\mathrm{o}}$ species than the species of the original source oil. Samples having a double peak shape of the $O_{\mathrm{o}}$ species, e.g., Samples 3282 and 3179 , reflected a mixture source from biological contributions and Arrow oil residues. In these two latter samples, long-chain
$O_{\mathrm{o}}$ species were more abundant than in Samples 3247 and 3251. This pattern reflected a greater amount of $O_{\mathrm{o}}$ species being sourced from the Arrow oil residues, e.g., in Samples 3282 and 3179. The petroleum contamination in Samples 3247 and 3251 was sourced mainly from recent human activities rather than the original Arrow spill (Yang et al. 2018). The predominance of the light $O_{\mathrm{o}}$ species with an obvious even-to-odd preference suggests a biological contribution, whereas those $O_{\mathrm{o}}$ species having a longer carbon-chain length represent more recent oil contamination.

The plots of the percentages of $O_{\mathrm{o}}$ species against carbon numbers, normalised to total $O_{\mathrm{o}}$ species in different samples, are shown in Fig. S3. For the spectra having a single bell shape, $O_{0}$ species attained a maximum of 5\%-6\% at carbon number 21 and 24. Maximum peaks in samples reflecting a biological contribution (i.e., Samples 3282, 3179, 3247, and 3251 ) accounted for $8 \%-13 \%$ of total $O_{\mathrm{o}}$ species for carbon numbers 16 and 20 . The second peak accounted for $2-5 \%$ around carbon number 30 . 
(a)

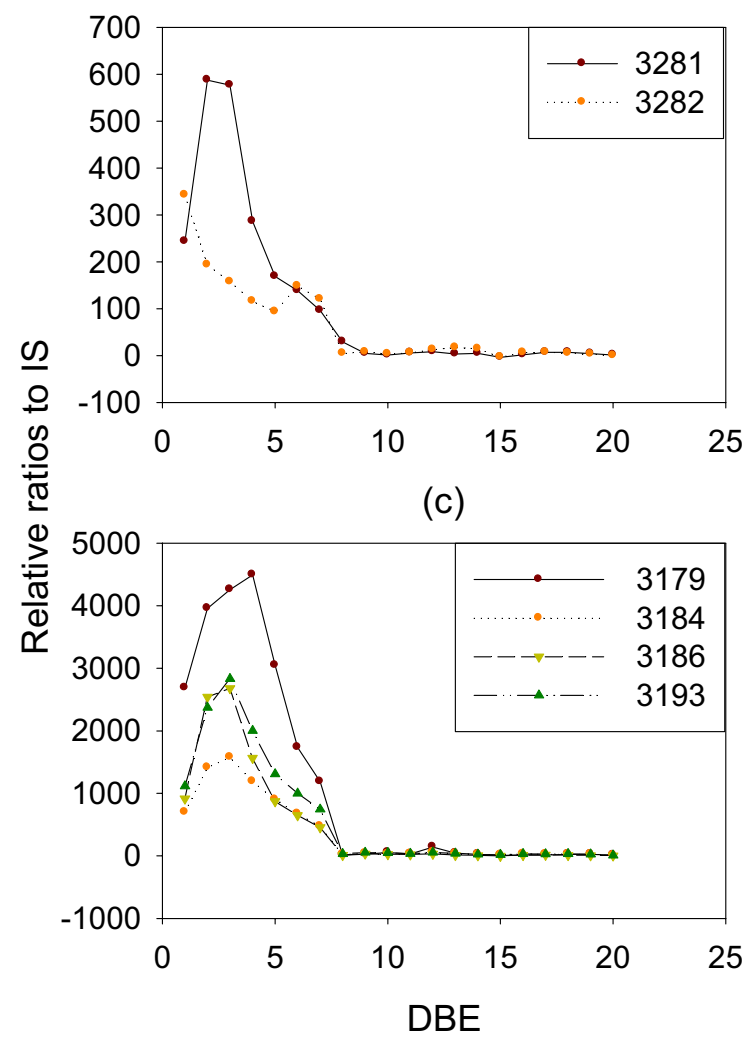

(b)

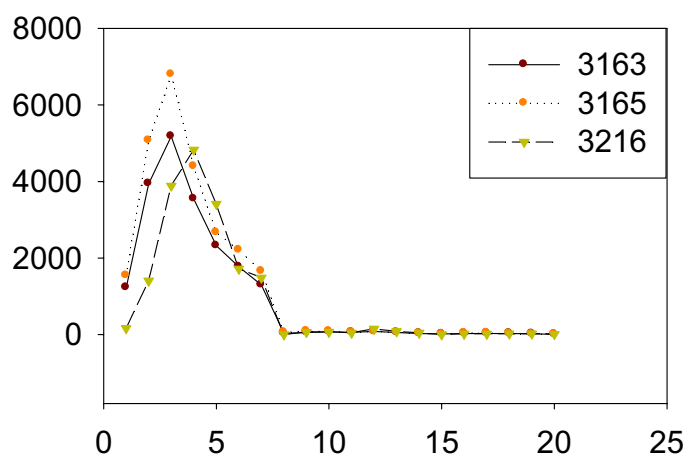

(d)

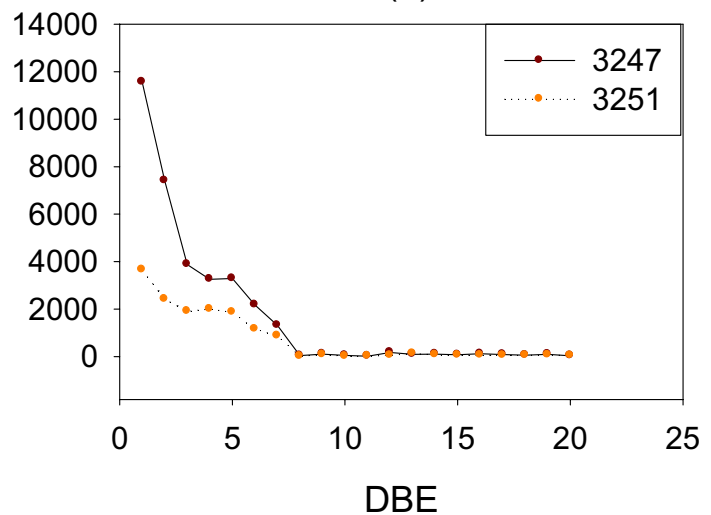

Fig. 5 Distribution profiles of total $O_{\mathrm{o}}$ species versus DBE number. a Source oil from the Arrow spill; b Arrow oil residues collected from Cape Auguet; c Arrow oil residues collected from Black Duck Cove; d sediments from the Port Hawkesbury marina area

\section{$O_{0}$ species versus DBE}

For all eleven samples, two patterns emerged in the plots of the relative abundance of total $O_{\mathrm{o}}$ species versus DBE (Fig. 5). The first pattern had $O_{\mathrm{o}}$ species with a DBE of 2-4 (1-3 cyclic rings) as the most abundant group in the source oil, Sample 3281, and most environmental oil residues (e.g., Samples 3216, 3163, 3165, and all oil residues from Black Duck Cove), accounting for 20-28\% of total NAFCs (Fig. S4). $O_{\mathrm{o}}$ species abundance then rapidly decreased for DBE numbers 4 to 7 to arrive at zero. We note, however, that the rate of decrease in abundance was slightly lower between DBE numbers 5 and 8 . The second pattern showed the abundance of total $O_{0}$ species to generally decrease as DBE values increased (i.e., Samples 3282, 3247, and 3251). We note a slightly slower rate of decrease (or even a small increase) for total $O_{\mathrm{o}}$ species for DBE numbers 4-7. The maximum peaks accounted for $25-35 \%$ of total $O_{\mathrm{o}}$ species (Fig. S4).

Most samples of the first pattern represent Arrow oil residues; samples with a marked biological contribution and a predominant even-over-odd carbon numbers in the short carbon-chain zone are members of the second pattern. The stability of NAFCs to weathering depends on the
NAFC carbon-chain length and DBE values (Misiti et al. 2014; Ray et al. 2014; Yang et al. 2017b). NAFCs with a greater number of naphthenic rings are more photosensitive than those with fewer rings (King et al. 2014; Leshuk et al. 2016). This difference in photosensitivity could explain why, in general, the higher saturated congeners were more abundant than unsaturated congeners. On the other hand, NAFCs having more cyclic rings tend to be more environmentally persistent and resistant to biodegradation (Misiti et al. 2014). However, biodegradation of NAFCs is sterically hindered by the presence of alkyl substitutions, which prevent $\beta$-oxidation in aliphatic structures or prevent ring opening in cyclic or aromatic structures (Yue et al. 2016). The observed slight increase or slower rate of decrease in abundance for $O_{0}$ species having DBE values of 4-7 can be ascribed to the preferable photolysis of hydrocarbons with polycyclic aromatic rings because these precursors are from the most photosensitive group (Yang et al. 2016).

\section{Identified $O_{0}$ species versus oxygen numbers}

Monocarboxylic acids ( $\mathrm{O}_{2}$ species) are the most abundant oxygen-containing acidic components in crude oil and 
diluted bitumen (Colati et al. 2013); however, solar radiation and microbial metabolism can add oxygen to the oil components and form higher-order oxygen classes $\left(\mathrm{O}_{4}-\mathrm{O}_{7}\right)$ (Ray et al. 2014; Vaughan et al. 2016). At the same time, biodegradation can decrease the relative abundance of $O_{1}$, $\mathrm{O}_{3}$, and $\mathrm{O}_{4}$ species (Kim et al. 2005; Yue et al. 2016). The $O_{\text {o }}$ species discussed above may, therefore, include a range of oxygen numbers. We distinguished $O_{\mathrm{o}}$ species having different oxygen numbers (from 1 to 8 ) from total $O_{\mathrm{o}}$ species to better evaluate $O_{\mathrm{o}}$ species variation between sampling sites (Fig. 6). In all samples, $\mathrm{O}_{2}$ species represented the most abundant class, followed by, with the exception of the Port Hawkesbury samples, comparable abundances of $\mathrm{O}_{3}$ and $\mathrm{O}_{4}$ species, and then by a pattern of decreased abundance as oxygen number increased. $\mathrm{O}_{6}$ to $\mathrm{O}_{8}$ species were not detected in most samples. The abundance of $O_{1}$ species was usually less than that of $O_{4}$ species. The abundance pattern of $\mathrm{O}_{2}$ species between samples was similar to the pattern for total $O_{\mathrm{o}}$ species.

Sample 3247 had the highest abundance of $\mathrm{O}_{2}$, followed by the two samples from Cape Auguet, Sample 3179 from Black Duck Cove, one sample from Indian Cove, and the three samples from Black Duck Cove. Both the source oil, Sample 3281, and the naturally weathered oil, Sample 3282,

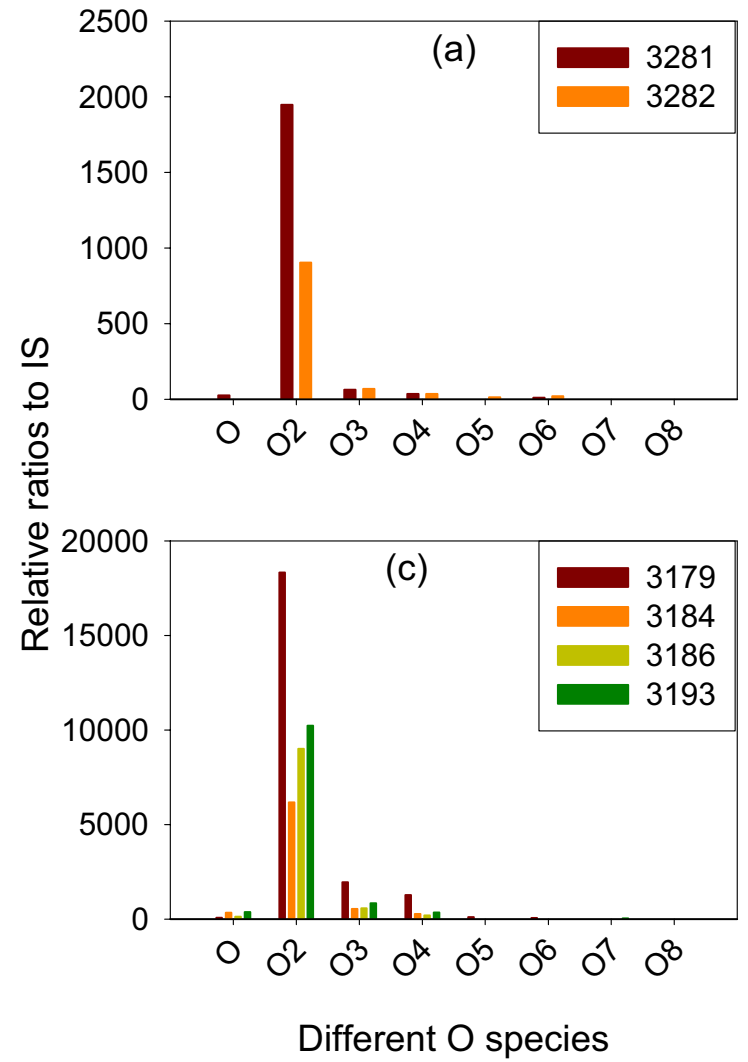

presented the lowest $\mathrm{O}_{2}$ abundance. The relative percentage of $\mathrm{O}_{2}$ species in all samples varied from $50-70 \%$ when normalised to total $O_{\mathrm{o}}$ species (Fig. S5). $O_{\mathrm{o}}$ species with higher oxygen numbers usually have a greater water solubility and bioavailability than those with lower oxygen numbers (Islam et al. 2013; Ray et al. 2014). Changes in the relative abundance of $O_{\mathrm{o}}$ species can occur due to the metabolism of $\mathrm{O}_{3}$ - to $\mathrm{O}_{8}$-NAFCs, oxidation of hydrocarbons, and $O_{1}$ - to $\mathrm{O}_{2}$-NAFCs in the natural environment (Yue et al. 2016). Physical abrasion from waves can deplete most $O_{\mathrm{o}}$ species that have a high water solubility from the stranded oil residues, especially at lower tidal level sites or shores exposed to high wave energy.

\section{Conclusions}

In this study, polar NAFCs were analysed and quantified by HPLC-HRMS. The natural weathering processes of oil from the sunken Arrow tanker along the shoreline of Chedabucto Bay, Nova Scotia, were evaluated. In all samples, $O_{\mathrm{o}}$ species with a high degree of saturation $(\mathrm{DBE}=0-4)$ were most abundant. All other species had a relatively low abundance. $\mathrm{O}_{2}$ species accounted for $50-70 \%$ of total $\mathrm{O}_{\mathrm{o}}$
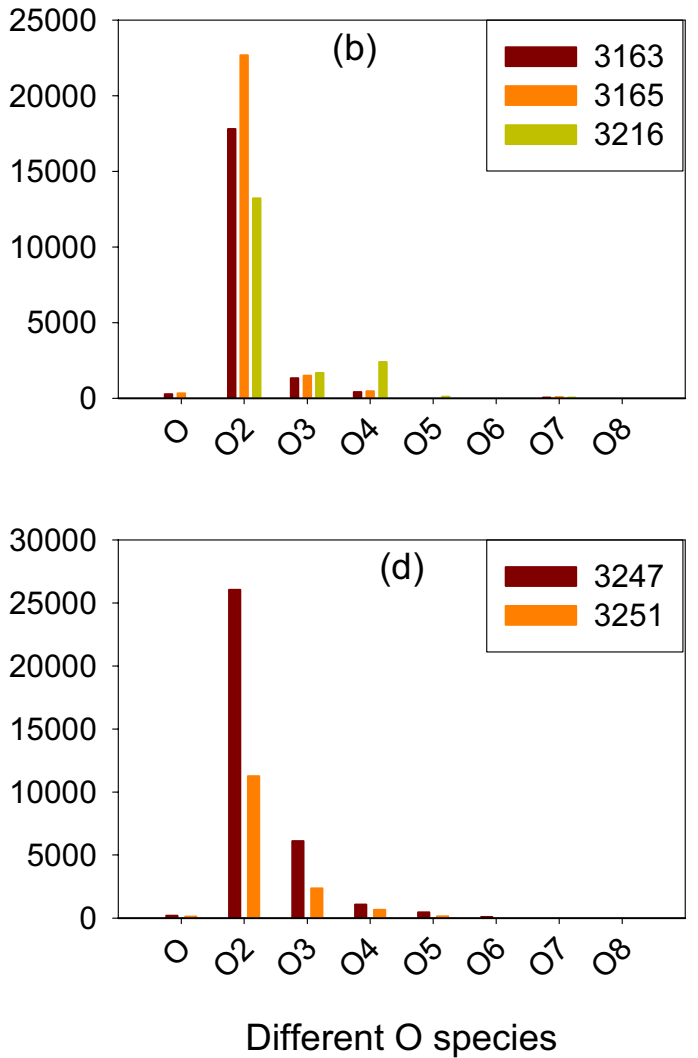

Fig. 6 Relative ratios of sub-total $O_{\mathrm{o}}$ species of different oxygen number. a Source oil from the Arrow spill; b Arrow oil residues collected from Cape Auguet; c Arrow oil residues collected from Black Duck Cove; d sediments from the Port Hawkesbury marina area 
species. Relative to the oil stored in the sunken tanker and the two sediment samples from Port Hawkesbury marina, the NAFCs within most Arrow oil residues-originating from the 1970 spill-were predominant with those of heavier molecular weight. The two samples collected from Port Hawkesbury reflected the predominance of a biological contribution with a smaller petroleum input as well, reflecting recent petroleum contamination. All Arrow oil residues contained NAFCs characteristic of petroleum. NAFCs in the oil residues have experienced severe weathering; therefore, the most resistant components to environmental weathering remained behind in the residues. The abundance of NAFCs in the Arrow oil residues varied between sites, a pattern that confirmed the importance of site-scale environmental conditions for understanding the natural attenuation of oil spilled in the environment.

Supplementary Information The online version contains supplementary material available at https://doi.org/10.1007/s12665-021-09959-y.

Funding This work was funded and supported by the Government of Canada's World Class Tanker Safety System (WCTSS) and Ocean Protection Plan programs.

Data availability The authors confirm that the data supporting the findings of this study are available within the article and its supplementary materials.

\section{Declarations}

Conflict of interest The authors declare that there is no conflicts of interest.

Open Access This article is licensed under a Creative Commons Attribution 4.0 International License, which permits use, sharing, adaptation, distribution and reproduction in any medium or format, as long as you give appropriate credit to the original author(s) and the source, provide a link to the Creative Commons licence, and indicate if changes were made. The images or other third party material in this article are included in the article's Creative Commons licence, unless indicated otherwise in a credit line to the material. If material is not included in the article's Creative Commons licence and your intended use is not permitted by statutory regulation or exceeds the permitted use, you will need to obtain permission directly from the copyright holder. To view a copy of this licence, visit http://creativecommons.org/licenses/by/4.0/.

\section{References}

Aeppli C, Carmichael CA, Nelson RK, Lemkau KL, Graham WM, Redmond MC, Valentine DL, Reddy CM (2012) Oil weathering after the deepwater horizon disaster led to the formation of oxygenated residues. Environ Sci Technol 46:8799-8807

Cheung SG, Wai HY, Shin PKS, Fahlman B (2010) Fatty acid profiles of benthic environment associated with artificial reefs in subtropical Hong Kong. Mar Pollut Bull 60:301-313
Clemente JS, Fedorak PM (2005) A review of the occurrence, analyses, toxicity and biodegradation of naphthenic acids. Chemosphere 60:585-600

Colati KAP, Dalmaschio GP, de Castro EVR, Gomes AO, Vaz BG, Romo W (2013) Monitoring the liquid/liquid extraction of naphthenic acids in brazilian crude oil using electrospray ionization FT-ICR mass spectrometry (ESI FT-ICR MS). Fuel 108:647-655

Dunn RJK, Welsh DT, Teasdale PR, Lee SY, Lemckert CJ, Meiziane $T$ (2008) Investigating the distribution and sources of organic matter in surface sediment of Coombabah Lake (Australia) using elemental isotopic and fatty acid biomarkers. Cont Shelf Res 28:2535-2549

Frank RA, Kavanagh R, Bumison BK, Aresnault G, Headley JV, Peru KM, Van Der Kraak G, Solomon KR (2008) Toxicity assessment of collected fractions from an extracted naphthenic acid mixture. Chemosphere 72:1309-1314

Frank RA, Fischer K, Kavanagh R, Solomon KR (2009) Effect of carboxylic acid content on the acute toxicity of oil sands naphthenic acids. Environ Sci Technol 43:266-271

Headley JV, Peru KM, Barrow MP (2016) Advances in mass spectrometric characterization of naphthenic acids fraction compounds in oil sands environmental samples and crude oil—a review. Mass Spectr Rev 35:311-328

Islam A, Cho Y, Yim UH, Shim WJ, Kim YH, Kim S (2013) The comparison of naturally weathered oil and artificially photo-degraded oil at the molecular level by a combination of SARA fractionation and FT-ICR MS. J Hazard Mater 263 Part 2:404-411

Katarina Huba A, Gardinali PR (2016) Characterizatoin of a crude oil weathering series by ultrahigh-resolution mass spectrometry using multiple ionization modes. Sci Total Environ 563-564:600-610

Kim S, Stanford LA, Rodgers RP, Marshall AG, Walters C, Qian K, Wenger LM, Mankiewicz P (2005) Micorbialalteration of the acidic and neutral polar NSO compounds revealed by Fourier transform ion cyclotron resonance mass spectrometry. Org Geochem 36:1117-1134

King S, Leaf P, Olson P, Ray M, Tarr M (2014) Photolytic and photocatalytic degrada-tion of surface oil from the deepwater horizon spill. Chemosphere 95:415-422

Lee K, Prince RC, Greer CW, Doe KG, Wilson JEH, Cobanli SE, Wohlgeschaffen GD, Alroumi D, King T, Tremblay GH (2003) Composition and toxicity of residual Bunker $\mathrm{C}$ fuel oil in intertidal sediments after 30 years. Spill Sci Technol Bull 8:187-199

Lemkau KL, McKenna A, Podgorski DC, Rodgers RP, Reddy CM (2014) Molecular evidence of heavy-oil weathering following the M/V Cosco Busan spill: insights from Fourier Transform Ion Cyclotron Resonance Mass Spectrometry. Environ Sci Technol 48:3760-3767

Leshuk T, Wong T, Linley S, Peru KM, Headley JV, Gu F (2016) Solar photocatalytic degradation of naphthenic acids in oil sands process-affected water. Chemosphere 144:1854-1861

McLafferty FW, Turecek F (1993) Interpretation of mass spectra, 4th edn. Mill Vallet, CA

Misiti TM, Tezel U, Pavlostathis SG (2014) Effect of alkyl side chain location and cyclicity on the aerobic biotransformation of naphthenic acids. Environ Sci Technol 45:7431-7437

Owens EH (1978) Mechanical dispersal of oil stranded in the littoral zone. J Fish Res Borad Can 35:563-572

Owens EH, Humphrey B, Sergy GA (1994) Natural cleaning of oil on two coarse-sediment shorelines on the Arctic and Atlantic coasts of Canada. Spill Sci Technol Bull 1:37-52

Owens EH, Prince RC, Taylor RB (2006) Natural attenuation of heavy oil on coarse sediment beaches: results from Black Duck Cove, Nova Scotia, Canada, over 35 years following the ARROW oil spill. https://inis.iaea.org/search/search.aspx?orig_q=RN:39112 848 
Owens EH, Taylor E, Humphrey B (2008) The persistence and character of stranded oil on coarse-sediment beaches. Mar Pollut Bull $56: 14-26$

Page JS, Kelly RT, Tang K, Smith RD (2007) Ionization and transmission efficiency in an electrospray ionization-mass spectrometry interface. J Am Soc Mass Spectrom 18:1582-1590

Ray PZ, Chen H, Podgorski DC, McKenna AM, Tarr MA (2014) Sunlight creates oxygenated species in water-soluble fractions of deepwater horizon oil. J Hazard Mater 280:636-643

Rowland SJ, Scarlett AG, Jones D, West CE, Frank RA, Hewitt LM (2011) Sterodial aromatic "naphthenic acids" in oil sands processaffected water: structural comparisons with environmental estrogens. Environ Sci Technol 45:9806-9815

Thomas ML (1977) Long term biological effects of Bunker C oil in the intertidal zone. In: Wolfe DA (ed) Fate and effects of petroleum hydrocarbons in marine organisms and ecosystems. Pergamon Press, New York, NY, pp 238-245

Vandermeulen JH, Buckley DE (1985) The Kurdistan oil spill of March 16-17, 1979: activities and observations of the Bedford Institute of Oceanography Response Team. Canadian Technical Report of Hydrography and Ocean Sciences. Bedford Institute of Oceanography, Dartmouth, Nova Scotia, pp 18-35

Vandermeulen JH, Gordon JH (1976) Reentry of 5-year oil stranded Bunker $\mathrm{C}$ fuel oil from a low-energy beach into water, sediments, and biota of Chedabucto Bay, Nova Scotia. J Fish Res Borad Can 33:2002-2010

Vandermeulen JH, Singh JG (1994) ARROW oil spill, 1970-90: Persistence of 20yr weathered Bunker C fuel oil. Can J Fish Aquat Sci 51:845-855

Vanderveen R, Mclnnis R, Brunswick P, Shang D, Headley JV, Peru KM, Hewitt LM (2017) Toxicity of naphthenic acids to invertebrates: extracts from oil sands process-affected water versus commercial mixtures. Environ Pollut 227:271-279

Vaughan PP, Wilson T, Kamerman R, Hagy ME, McKenna A, Chen H, Jeffrey WH (2016) Photochemical changes in water accommodated fractions of MC252 and surrogate oil created during solar exposure as determined by FT-ICR MS. Mar Pollut Bull 104:262-268

Wan Y, Wang B, Khim JS, Hong S, Shim WJ, Hu J (2014) Naphthenic acids in coastal sediments after the Hebei Spirit oil spill: a potential indicator for oil contamination. Environ Sci Technol 48:4153-4162

Wang Z, Fingas M, Sergy G (1994) Study of 22-year-old ARROW oil samples using biomarker compounds by GC/MS. Environ Sci Technol 28:1733-1746
Yang Z, Hollebone BP, Brown CE, Yang C, Wang Z, Zhang G, Lambert P, Landriault M, Shah K (2016) The photolytic behavior of diluted bitumen in simulated seawater by exposed to the natural sunlight. Fuel 186:128-139

Yang Z, Hollebone HP, Laforest S, Lambert P, Brown CE, Yang C, Shah K, Landriault M, Goldthorp M (2017a) Occurrence, source and ecological assessment of baseline hydrocarbons in the intertidal marine sediments along the shoreline of Douglas Channel to Hecate Strait in British Columbia. Mar Pollut Bull 122:450-455

Yang Z, Zhang G, Hollebone BP, Brown CE, Yang C, Lambert P, Wang Z, Landriault M, Shah K (2017b) Fate of oxygenated intermediates in solar irradiated diluted bitumen mixed with saltwater. Environ Pollut 231:622-634

Yang Z, Shah K, Laforest S, Hollebone BP, Lambert P, Brown CE, Yang C, Goldthorp M (2018) A study of the 46-year-old arrow oil spill: Persistence of oil residues and variability in oil contamination along Chedabucto Bay, Nova Scotia, Canada. J Clean Prod 198:1459-1473

Yang C, Zhang G, Serhan M, Koivu G, Yang Z, Hollebone B, Lambert P, Brown CE (2019) Characterization of naphthenic acids in crude oils and refined petroleum products. Fuel 255.

Yue S, Ramsay BA, Wang J, Ramsay JA (2016) Biodegradation and detoxification of naphthenic acids in oil sands process affected waters. Sci Total Environ 572:273-279

Zhang G, Yang C, Liu Y, Yang Z, Wang Z, Landriault M, Hollebone BP, Lambert P, Brown CE (2014) Improved approach to quantitatively and qualitatively characterize carboxylic acid isomers in commercial naphthenic acids mixture by HPLC-high resolution Orbitrap mass spectrometer technique. In: Proceedings of the 37th AMOP technical seminar on environmental contamination and response. Environment and Climate Change Canada, Ottawa, ON, pp 848-869

Zhang Y, Xue J, Liu Y, Gamal El-Din M (2016) Treatment of oil sands process-affected water using membrane bioreactor coupled with ozonation: a comparative study. Chem Eng J 302:485-497

Publisher's Note Springer Nature remains neutral with regard to jurisdictional claims in published maps and institutional affiliations. 